\title{
Video Article DNA Extraction from Paraffin Embedded Material for Genetic and Epigenetic Analyses
}

\author{
Larissa A. Pikor* ${ }^{1,2}$, Katey S. S. Enfield ${ }^{{ }^{1,2}}$, Heryet Cameron ${ }^{3}$, Wan L. Lam ${ }^{1,2,4}$ \\ ${ }^{1}$ Department of Integrative Oncology, BC Cancer Research Centre \\ ${ }^{2}$ Interdisciplinary Oncology Program, University of British Columbia - UBC \\ ${ }^{3}$ Photography/Video Production, Multi-Media Services, BC Cancer Agency \\ ${ }^{4}$ Department of Pathology and Laboratory Medicine, University of British Columbia - UBC \\ *These authors contributed equally
}

Correspondence to: Larissa A. Pikor at Ipikor@bccrc.ca

URL: https://www.jove.com/video/2763

DOI: doi:10.3791/2763

Keywords: Genetics, Issue 49, DNA extraction, paraffin embedded tissue, phenol:chloroform extraction, genetic analysis, epigenetic analysis

Date Published: 3/26/2011

Citation: Pikor, L.A., Enfield, K.S., Cameron, H., Lam, W.L. DNA Extraction from Paraffin Embedded Material for Genetic and Epigenetic Analyses. J. Vis. Exp. (49), e2763, doi:10.3791/2763 (2011).

\section{Abstract}

Disease development and progression are characterized by frequent genetic and epigenetic aberrations including chromosomal rearrangements, copy number gains and losses and DNA methylation. Advances in high-throughput, genome-wide profiling technologies, such as microarrays, have significantly improved our ability to identify and detect these specific alterations. However as technology continues to improve, a limiting factor remains sample quality and availability. Furthermore, follow-up clinical information and disease outcome are often collected years after the initial specimen collection. Specimens, typically formalin-fixed and paraffin embedded (FFPE), are stored in hospital archives for years to decades. DNA can be efficiently and effectively recovered from paraffin-embedded specimens if the appropriate method of extraction is applied. High quality DNA extracted from properly preserved and stored specimens can support quantitative assays for comparisons of normal and diseased tissues and generation of genetic and epigenetic signatures ${ }^{1}$. To extract DNA from paraffin-embedded samples, tissue cores or microdissected tissue are subjected to xylene treatment, which dissolves the paraffin from the tissue, and then rehydrated using a series of ethanol washes. Proteins and harmful enzymes such as nucleases are subsequently digested by proteinase $\mathrm{K}$. The addition of lysis buffer, which contains denaturing agents such as sodium dodecyl sulfate (SDS), facilitates digestion ${ }^{2}$. Nucleic acids are purified from the tissue lysate using buffer-saturated phenol and high speed centrifugation which generates a biphasic solution. DNA and RNA remain in the upper aqueous phase, while proteins, lipids and polysaccharides are sequestered in the inter- and organic-phases respectively. Retention of the aqueous phase and repeated phenol extractions generates a clean sample. Following phenol extractions, RNase A is added to eliminate contaminating RNA. Additional phenol extractions following incubation with RNase $A$ are used to remove any remaining enzyme. The addition of sodium acetate and isopropanol precipitates DNA, and high speed centrifugation is used to pellet the DNA and facilitate isopropanol removal. Excess salts carried over from precipitation can interfere with subsequent enzymatic assays, but can be removed from the DNA by washing with $70 \%$ ethanol, followed by centrifugation to re-pellet the DNA ${ }^{3}$. DNA is re-suspended in distilled water or the buffer of choice, quantified and stored at $-20^{\circ} \mathrm{C}$. Purified DNA can subsequently be used in downstream applications which include, but are not limited to, PCR, array comparative genomic hybridization ${ }^{4}$ (array CGH), methylated DNA Immunoprecipitation (MeDIP) and sequencing, allowing for an integrative analysis of tissue/tumor samples.

\section{Video Link}

The video component of this article can be found at https://www.jove.com/video/2763/

\section{Protocol}

\section{Procedural notes}

- Xylene and phenol are toxic chemicals and should be handled in a fumehood. Refer to the material safety data sheet (MSDS) before use.

- Xylene dissolves certain plastics; polypropylene tubes should be used as they tolerate these compounds.

- Special tips may be purchased that contain an internal charcoal stopper. This prevents the xylene from dissolving any rubber components in the pipette. Alternatively, filter tips can be used.

\section{Paraffin removal}

1. In a fumehood, add $800 \mu$ l of xylene (VWR, CABDH6216-4) to the labeled tube containing your specimen and place on a rocker with gentle shaking for 5 to 15 minutes to dissolve the paraffin. 
2. Pellet the sample by spinning at max speed $(14,000 \mathrm{rpm}$ or $16000 \mathrm{xg})$ in a microcentrifuge for 3 minutes. Carefully withdraw the $\mathrm{xylene}$ supernatant and dispose in a polypropylene tube for discard in the xylene waste. Be careful not to disturb the pellet.

3. Repeat xylene wash steps 1 and 2until paraffin is fully dissolved. This usually requires two to three washes, depending on the size of the tissue sample. A fully dissolved sample will appear soft, and will sometimes lose its structural integrity. The integrity of the sample can be gently assessed with a pipette tip.

\section{Ethanol rehydration}

1. Add $800 \mu \mathrm{l}$ of $100 \%$ ethanol $(\mathrm{v} / \mathrm{v})$ molecular biology grade ethanol, vortex, then spin for 3 minutes at $14,000 \mathrm{rpm}$ in microcentrifuge. Remove the ethanol supernatant, being careful not to disturb the pellet.

2. Add $800 \mu \mathrm{l}$ of $70 \%$ ethanol $\left(100 \%(\mathrm{v} / \mathrm{v})\right.$ ethanol diluted in distilled water $\left.\left(\mathrm{dH}_{2} \mathrm{O}\right)\right)$, vortex, and spin for 3 minutes at $14,000 \mathrm{rpm}$. Carefully remove the ethanol supernatant.

3. Add $800 \mu \mathrm{l}$ of $50 \%$ ethanol $\left(100 \%\right.$ (v/v) ethanol diluted in distilled water $\left(\mathrm{dH}_{2} \mathrm{O}\right)$ ), vortex, and spin for 5 minutes at $14,000 \mathrm{rpm}$. Carefully remove as much ethanol as possible by pipetting. Be extremely careful of disturbing the pellet at this point as fully rehydrated tissue will not pellet as well as dehydrated tissue.

4. After removing the ethanol supernatant, air-dry the pellet for 5 minutes, being careful not to over dry.

\section{Tissue digestion}

1. Add 200-500 $\mu \mathrm{l}$ of Lysis Buffer (formula below). Re-suspend the pellet using a pipette tip or a vortex. Extra effort at this point to fully resuspend the tissue will result in a more complete digestion of the sample and a better yield of DNA.

2. Incubate samples at $56^{\circ} \mathrm{C}$ in a water bath or heating block.

3. For tissue cores, spike $20 \mu \mathrm{l}$ of proteinase $\mathrm{K}(20 \mathrm{mg} / \mathrm{ml}$ stock solution, Invitrogen, AM2548) morning and evening.

4. Repeat above digestion steps for 2 to 5 days until the tissue is fully dissolved.

\section{Lysis Buffer}

- $10 \mathrm{mM}$ Tris- $\mathrm{HCl} \mathrm{pH} 8.0$

- $100 \mathrm{mM}$ EDTA pH 8.0

- $50 \mathrm{mM} \mathrm{NaCl}$

- $0.5 \%$ SDS

- $200 \mu \mathrm{g} / \mathrm{ml}$ proteinase $\mathrm{K}$ (add just before use)

\section{DNA clean up}

1. Add an equal volume of buffer saturated phenol (Fisher, BP1750l-400) and mix by inversion. Spin for at least 5 minutes at 14,000 rpm in microcentrifuge.

2. Transfer the aqueous layer to a new tube. Note the interphase: is there a lot of white material?

3. Repeat steps 1 and 2 on the aqueous fraction until the interphase is clear (typically 3 or more times). Perform back extractions* when the interphase is fuzzy to increase final yield.

4. Once the interphase is clear, add an equal volume of phenol:chloroform:isoamyl alcohol (25:24:1) (Fisher, BP1752I-400) to the extracted aqueous fraction of your sample. Mix for 5 minutes and then spin for 5 minutes at 14,000 rpm. Thisreduces residual phenol and further sharpens the interphase, facilitating extraction of the aqueous layer

5. Remove the aqueous layer to a new tube and treatwith RNase A at $100 \mu \mathrm{g} / \mathrm{ml}$ for 1 hour at $37^{\circ} \mathrm{C}$.

6. Repeat steps 1 to 4 to remove any remaining RNase A and collect the aqueous fraction. You should only need 1 or 2 buffer saturated phenol steps as there should be much less protein to remove than in the initial lysate.

${ }^{*}$ To perform back extractions add $50-100 \mu \mathrm{l}$ of $\mathrm{dH}_{2} 0$ to the sample tube containing the interphase and organic portion. Invert the tube to mix, and spin the sample at $14,000 \mathrm{rpm}$ in a microcentrifuge for 5 minutes. Collect the aqueous phase and add it to the previously acquired aqueous extraction. Continue back extractions until the interphase is clear.

\section{DNA precipitation}

1. Estimate the volume of your collected aqueous layer.

2. Add $1 / 10$ the volume of $3 \mathrm{M}$ sodium acetate $\mathrm{pH} 5.2$ and 1 volume of $100 \%$ isopropanol $(\mathrm{v} / \mathrm{v}$ ) molecular biology grade (or 2.5 volumes of $100 \%$ ethanol).

3. Mix well and put on ice or in a $-20^{\circ} \mathrm{C}$ freezer for 30 minutes or overnight.

4. Spin at maximum speed $(14,000 \mathrm{rpm})$ at $4^{\circ} \mathrm{C}$ in microcentrifuge for 10 minutes

5. Discard the supernatant.

6. Wash the pellet with $70 \%$ ice cold ethanol to remove unwanted salts.

7. Re-suspend the pellet in the buffer of choice (usually $\mathrm{dH}_{2} \mathrm{O}$ ).

\section{DNA quantification}

1. Quantify the concentration of DNA. The A260:A280 ratio should be $\sim 1.8$. For small quantities of DNA, measurement using a NanoDrop spectrophotometer is preferred. 
2. Following quantification, gel electrophoresis should be performed to test the quality of your sample DNA and determine whether contaminating RNA has been completely degraded .

3. High quality extracted DNA is now suitable for downstream applications, or can be stored at $-20^{\circ} \mathrm{C}$ for later use. If RNA is still present in your sample, repeat the DNA clean up and precipitation steps, and re quantify and qualify the quality of your samples.

\section{Discussion}

Biopsied or surgically excised tissues for histopathologic analysis and diagnosis are often formalin fixed and paraffin embedded (FFPE) for long term storage. With the growing interest in understanding the genetic basis of disease, the ability to extract DNA from these samples represents an invaluable source of diagnostic material that can be used for genomic analysis and translational studies. Historically FFPE samples were not considered a viable source for molecular analysis as nucleic acids may be heavily modified by protein-nucleic acid and protein-protein cross linking ${ }^{6}$. However, the discovery that protease digestion releases fragmented nucleic acids which are suitable for downstream analyses including $\mathrm{PCR}$, array $\mathrm{CGH}$, sequencing and methylation profiling, enables the use of these valuable specimens for genetic analysis ${ }^{6}$.

DNA extraction from paraffin-embedded tissues is a robust procedure that relies on differential solubility to purify DNA. Extracted DNA quality and quantity and the success of subsequent DNA amplification is dependent on a number of parameters before, during and after extraction. These include, but are not limited to: type and amount of tissue, the type of fixative used for tissue preservation, the duration of fixation, age of the paraffin block and storage conditions, as well as the length of the desired DNA segment to be amplified ${ }^{1,7}$. Removal of paraffin from the tissue is the most critical step for successful extraction as undissolved paraffin leads to poor sample quality and inhibition of PCR amplification.

\section{Disclosures}

No conflicts of interest declared.

\section{Acknowledgements}

We would like to thank members of the Lam lab for their evaluation and critiques of this video and article. This work was supported by funds from the Canadian Institutes for Health Research.

\section{References}

1. Santos, M.C., Saito, C.P. \& Line, S.R. Extraction of genomic DNA from paraffin-embedded tissue sections of human fetuses fixed and stored in formalin for long periods. Pathol Res Pract 204, 633-6 (2008).

2. Hilz, H., Wiegers, U. \& Adamietz, P. Stimulation of proteinase K action by denaturing agents: application to the isolation of nucleic acids and the degradation of 'masked' proteins. Eur J Biochem 56, 103-8 (1975).

3. Joseph Sambrook, D.R. Molecular Cloning: A Laboratory Manual, (Cold Spring Harbor Laboratory Press, Cold Spring Harbor, New York, 2001).

4. Kennett, J.Y., Watson, S.K., Saprunoff, H., Heryet, C. \& Lam, W.L. Technical demonstration of whole genome array comparative genomic hybridization. J Vis Exp (2008).

5. Thu, K.L. et al. Methylated DNA immunoprecipitation. J Vis Exp (2009).

6. Tang, W. et al. DNA extraction from formalin-fixed, paraffin-embedded tissue. Cold Spring Harb Protoc 2009, pdb prot5138 (2009).

7. Hongxin Fan, M.L.G. DNA Extraction from Paraffin-Embedded Tissues. Molecular Pathology Protocols 49, 1-4 (2001). 